\title{
Clinical Observation of Minimally Invasive Surgery and Conservative Treatment for Ankle Degenerative Osteoarthropathy
}

\author{
Bo Gou ${ }^{1}$, Xiaotao Wang ${ }^{2, *}$ \\ ${ }^{1}$ Department of Bone and Joint Surgery \\ ${ }^{2}$ Department of Minimally Invasive Orthopedics, Renmin Hospital, Hubei University of Medicine, Shiyan, \\ Hubei, China,442000
}

Address: Chaoyang District Road No. 39, Shiyan City, Hubei Prov, P.R. China, 442000

*Corresponding author: hubeiwenbo@qq.com

Keywords: minimally invasive surgery, conservative treatment, ankle degenerative osteoarthropathy, clinical effect

\begin{abstract}
The authors observed and analyzed the clinical effect of minimally invasive surgery and conservative treatment for ankle degenerative osteoarthropathy. In the paper, 90 patients suffering ankle degenerative osteoarthropathy who were received and cured by this hospital from January, 2014 to January, 2015 are selected, who were grouped at random. Each group contained 45 cases. The paper took conservative treatment for the patients in the control group and minimally invasive surgery for the patients in the observation group, and compared the clinical effect of the two groups. Results show that the excellent and good rate of the observation group was $86.7 \%$, the excellent and good rate of the control group was $82.2 \%$, and the difference of the excellent and good rate between the two groups $\mathrm{P}>0.05$. After treatment, the joint function score of the observation group was much higher than that of the control group, VAS of the observation group was much lower than that of the control group, $\mathrm{P}<0.05$, and the difference was significant. In conclusion, the minimally invasive surgery could improve the ankle joint function of the patients suffering ankle degenerative osteoarthropathy and ease their pain.
\end{abstract}

\section{INTRODUCTION}

The ankle degenerative osteoarthropathy is a type of common clinical degenerative osteoarthropathy, and the main manifestations of degenerative osteoarthropathy are arthralgia, swelling and limitation of activity [1]. The main pathogenic factor of this disease is trauma. If it is not cured reasonably or in time, it may cause the degenerative change of articular cartilage, joint deformity, etc. At present, there are two clinic treatment methods for it: conservative treatment and operative treatment [2]. In order to explore the safest and most effective method for the treatment of the ankle degenerative osteoarthropathy, in this article, we take 90 patients suffering the ankle degenerative osteoarthropathy as the research objects, and observe and analyze the clinical effect of minimally invasive surgery and conservative treatment for the ankle degenerative osteoarthropathy respectively.

\subsection{General data}

The duration of the research was from January, 2014 to January, 2015, the research objects were 90 patients suffering the ankle degenerative osteoarthropathy, and they received the imageological examination combined their clinical manifestations and signs when they were admitted. Exclude the patients having congenital dysplasia, severe internal medical diseases and the history of arthroscopic surgery and the special populations (children, pregnant women, lactating women, etc) Group them with the random number table. The control group: total 45 cases, contained 24 male patients and 21 female patients between 20 and 65 years old, the average age was (28.5 \pm 4.0$)$ years old, and 23 patients whose right ankles were injured and 22 patients whose left ankles were injured. The observation group: total 45 cases, contained 25 male patients and 20 female patients between 22 and 65 years old, the average age was $(28.5 \pm 4.0)$ years old, and 24 patients whose right ankles were 
injured and 21 patients whose left ankles were injured. All penitents knew and agreed the research and signed the informed consent forms, and their general data were tested by the statistical method. When $\mathrm{P}>0.05$, it means the data are comparable.

\subsection{Method}

Take conservative treatment for the patients in the control group, including the conventional medical treatment and functional rehabilitation training, and choose Glucosamine Hydrochloride Capsules as the medicine (manufacturer: Zhejiang Chengyi Pharmaceutical Co., Ltd., approval number: G.Y.Z.Z. H20120603). The patients take the medicine for (240-480) mg orally everyday (in three separate doses). In addition, inject hyaluronic acid into the articular cavity $20 \mathrm{ml} /$ once/ day, total 7 times/ week.

Take minimally invasive surgery for the patients in the observation group. The patients shall be in the supine position with local anesthesia. Open an incision with an arthroscope (take the inner edge of the tibialis anterior muscle of the ankle as the inner entrance to separate the subcutaneous tissue, and take the left anterior direction as the outer entrance under the arthroscope), inject the mixed injection ( $1 \mathrm{ml}$ of epinephrine and $3000 \mathrm{ml}$ of normal saline) continuously, examine the affected part by arthroscopy, take countertraction and plantar flexion, clear the hyperplastic synovium, repair and strip the cartilage debris, etc. Begin to take the rehabilitation training after operation and take weight training after 2 weeks. Take the conventional conservative treatment for the patients after operation as same as the control group.

\subsection{Observation and evaluation indexes}

After three months of treatment, evaluate the two groups: (1) the clinical effect: excellent: the symptoms disappeared, and the ankle function returned to be normal completely; good: the symptoms disappeared (the symptom score $\geq 50 \%$ ) , and the ankle function returned to be normal basically; medium: the symptoms were improved, but the symptom score $<50 \%$; bad: fail to meet the above standards. (2) Ankle function score: evaluate it by American Orthopaedic Foot and Ankle Society (AOFAS), Ankle Hindfood Scale; the total score was 100, and the score was in direct proportion to the ankle function [3]. (3) Pain score: evaluate it by VAS (visual analogue scale); the higher the score, the more acute the pain [4].

\subsection{Statistical method}

Take \% to express the clinical enumeration data, $\bar{x} \pm s$ to express the measurement data and SPSS19.0 software for the data processing; the significance testing methods are $\chi^{2}$ and t-test; when $\mathrm{P}<0.05$, it means the difference between the two groups has statistical significance.

\section{RESULTS}

\subsection{Clinical effect}

The excellent and good rate of the observation group is $86.7 \%$ (39/45) and the excellent and good rate of the control group is $82.2 \%$ (37/45); comparing the difference of the excellent between the two groups, $\mathrm{P}>0.05$, so the difference doesn't have the statistical significance as shown in Table 1.

Table 1. Comparison of the clinical effect between the two groups

\begin{tabular}{ccccccc}
\hline Group & $\begin{array}{c}\text { Number } \\
\text { of cases } \\
\text { (cases) }\end{array}$ & $\begin{array}{c}\text { Excellent } \\
\text { (cases) }\end{array}$ & $\begin{array}{c}\text { Good } \\
\text { (cases) }\end{array}$ & $\begin{array}{c}\text { Medium } \\
\text { (cases) }\end{array}$ & $\begin{array}{c}\text { Bad } \\
\text { (cases) }\end{array}$ & $\begin{array}{c}\text { Excellent } \\
\text { and good } \\
\text { rate (\%) }\end{array}$ \\
\hline $\begin{array}{c}\text { Observation } \\
\text { group }\end{array}$ & 45 & 25 & 14 & 5 & 1 & 86.7 \\
$\begin{array}{c}\text { Control } \\
\text { group }\end{array}$ & 45 & 24 & 13 & 6 & 2 & 82.2 \\
$\chi^{2}$ & $/$ & $/$ & $/$ & $/$ & $/$ & 0.35 \\
P & $/$ & $/$ & $/$ & $/$ & $/$ & $>0.05$ \\
\hline
\end{tabular}

\subsection{Ankle function score and pain score}

Before treatment, comparing VAS and the ankle function scores of the patients between the two 
groups, $\mathrm{P}>0.05$, the difference doesn't have the statistical significance. After treatment, the joint function score of the observation group is much higher than that of the control group, VAS of the observation group is much lower than that of the control group, $\mathrm{P}<0.05$, so the difference is significant as shown in Table 2.

Table 2. Comparison of the ankle function and pain scores between the two groups

\begin{tabular}{cccccc}
\hline Group & $\begin{array}{c}\text { Treatment } \\
\text { stage }\end{array}$ & $\begin{array}{c}\text { Observation } \\
\text { group }\end{array}$ & $\begin{array}{c}\text { Control } \\
\text { group }\end{array}$ & $\mathrm{t}$ & $\mathrm{P}$ \\
\hline \multirow{2}{*}{ VAS } & $\begin{array}{c}\text { Before } \\
\text { treatment } \\
\text { After } \\
\text { treatment } \\
\text { Before }\end{array}$ & $7.1 \pm 2.1$ & $7.0 \pm 2.0$ & 0.231 & $>0.05$ \\
Ankle & $\begin{array}{c}\text { treatment } \\
\text { After } \\
\text { function }\end{array}$ & $52.6 \pm 0.5$ & $3.0 \pm 0.9$ & 5.212 & $<0.05$ \\
& $\begin{array}{c}\text { treatment } \\
\text { trent }\end{array}$ & $84.2 \pm 5.0$ & $65.6 \pm 2.0$ & 0.213 & $>0.05$ \\
\hline
\end{tabular}

\section{DISCUSSIONS}

Normally, the ankle joint is stable and balanced dynamically and statically by the articular ligament, bony structure and muscle tendon. However, if the stable joint structure is damaged and is not cured effectively, it will cause the ankle degenerative change. Some medical researches show that the main manifestations of the ankle degenerative osteoarthropathy are arthrocele, pain, amyotrophy, dysfunction, etc. Usually, this disease begins with the degeneration of arthrodial cartilage, and gradually develops to the sclerosis of joint capsule and subchondral bone and the change of the important structures of other important joints [5].

The ankle degenerative osteoarthropathy can be diagnosed by normal imageological examination, but the treatment for it is a difficulty for clinicians. At present, there is no special therapy for the degenerative osteoarthropathy clinically, the main therapeutic principle is to alleviate the patients' clinical symptoms and prevent the joint function from degenerating continuously, and the main therapeutic methods are conservative treatment and operative treatment.

Conservative treatment mainly contains physical therapy, drug therapy (pain killer, anti-inflammatory agent, etc) and cinesiatrics. However, it has some limitations. For example, the exposure will cause the disease to be cured difficultly. Based on this, the clinical researchers have created the new therapeutic methods continuously. In recent years, many researchers have verified that viscoelastic supplement is a good choice to cure the ankle degenerative osteoarthropathy. In this research, we injected sodium hyaluronate into the joint cavities of the patients and got good effect, and the excellent and good rate was $82.2 \%$. The mechanism is to alleviate the clinical symptoms of the patients by improving the mechanism of muscle around joint and the stability of the ligament joint capsule, changing the mechanical environment in the joint, protecting the cartilage with viscoelastic substance, nutrition and the inflammatory suppression of anti-inflammatory agent, which has verified that the conservative treatment can alleviate the clinical symptoms of the patients effectively with ideal clinical effect again. However, patients shall take the functional training automatically, and the compliance of the patients is possible to influence the function rehabilitation efficacy.

Similarly, operative treatment is a therapy attracting much attention, but the traditional open operation has some disadvantages, such as big wounds and postoperative complications, which make the patients have many scruples. In recent years, with the development and application of the minimally invasive technology, the arthroscope has played a more and more important role in the diagnosis and treatment of various joint and bone damages. The best operation indication of the arthroscope is the anterior ankle impingement syndrome. The prognosis is favorable after treatment, and there is no report about the patients transferred to major operation during the process [6]. In this research, we took minimally invasive surgery with arthroscopy for the patients in the observation group. After treatment, the excellent and good rate of the observation group was $86.7 \%$. Compared 
with that of the control group, the difference was not significant and was similar to the conclusion of the report of Kuang Li et al [7], which has verified that the clinical effect of the ankle degenerative osteoarthropathy by minimally invasive surgery is ideal.

In addition, we recorded the joint function score and VAS of the patients in the two groups before and after treatment. The results showed that, after treatment, the joint function score of the observation group was much higher than that of the control group, VAS of the observation group was much lower than that of the control group, $\mathrm{P}<0.05$, and the difference was significant. It is visible that the minimally invasive surgery can alleviate the patients' pain and improve their joint function effectively compared with the conservative treatment. We think it is closely related to the action mechanism of the minimally invasive surgery. Compared with the conservative treatment, the biggest advantages of the minimally invasive surgery are to dispose the damaged cartilage directly, clean the inflammatory factor in the joint and improve the soft (or bone) tissue impingement, to further effectively alleviate the pain and synovium inflammation caused by the edema of subchondral bone, and provide favorable conditions for the patients' postoperative functional rehabilitation and relieving pain.

To sum up, the minimally invasive surgery can improve the ankle joint function of the patients suffering ankle degenerative osteoarthropathy and ease their pain.

\section{REFERENCES}

[1] Osti L, Del Buono A, Maffulli N, “Arthroscopic debridement of the ankle for mild to moderate osteoarthr-itis: a midterm follow-up study in former professional soccer players”, J Orthop Surg Res,2016.

[2] Iwasa K, Kanzaki N, Fujishiro T, Hayashi S, Hash-imoto S, “Arthroscopic ankle arthrodesis for osteoarthritis in a patient with kashin-beck disease”, Case Rep Med,2014.

[3] Kim YS1, Youn HK2, Kim BS3, Choi YJ4, Koh YG4, “Arthroscopic evaluation of persistent pain following supramalleolar osteotomy for varus ankleosteo-arthr-itis”,Knee Surg Sports Traumatol Arthrosc,vol.09pp,60-67,2016.

[4] Hendrickx RP1, de Leeuw PA, Golano P, van Dijk CN, Kerkhoffs GM. "Safety and efficiency of posterior arthroscopic ankle arthrodesis”, Knee Surg Sports Traumatol Arthrosc, vol.08, pp.2420-2426,2015.

[5] Yasui Y, Vig KS, Murawski CD, Desai P, Savage-Elliott I, Kennedy JG. “Open Arthroscopic Ankle Arthrodesis: A Comparison of Subsequent Procedures in a Large Database”, J Foot? Ankle? Surg, 2014.

[6] Duan X, Yan L, Yin L. “Arthroscopic arthrodesis for ankle arthritis without bone graft”, J Orthop Surg Res, vol.12, pp.242-246,2016.

[7] Piraino JA1, Lee MS2. “Arthroscopic Ankle Arthrodesis: An Update”, Clin Podiatr Med Surg. Vol.34, pp.503-514,2016 